\title{
DIVISIONES BANANERAS Y MEMORIA: UN ACERCAMIENTO AL LEGADO DE LAS CIUDADES BANANERAS DE LA UNITED FRUIT COMPANY EN CENTROAMÉRICA DURANTE EL SIGLO XX
}

\section{BANANA DIVISIONS AND MEMORY: AN APPROACH TO THE LEGACY OF THE BANANA CITIES OF THE UNITED FRUIT COMPANY IN CENTRAL AMERICA DURING THE 20TH CENTURY}

\author{
Luis Conejo Barboza*
}

\begin{abstract}
Resumen: El presente artículo pretende analizar, a partir de la historia de las organizaciones, la relación entre memoria y las ciudades bananeras construidas por la United Fruit Company en Centroamérica durante el siglo XX. Se parte de las ideas planteadas por Charles Booth, Peter Clark, Agnes Delahaye, Stephen Procter y Michael Rowlinson con respecto al uso de la memoria social para estudiar las prácticas mnemónicas de las empresas y cómo desde esta perspectiva las compañías construyen un legado histórico para sus empleados y el público en general. Utilizando fuentes impresas de la compañía, como revistas empresariales, reportes para socios, postales, así como testimonios escritos de extrabajadores bananeros, la investigación trata de identificar la forma en cómo las ciudades bananeras se convirtieron y fueron construidas como lugares de la memoria. La ciudad bananera surge a partir de los programas del llamado "bienestar corporativo" de inicios del siglo anterior, que buscaba entre otras cosas, no solo la lealtad de los empleados, sino también que estos se sintieran bien y a gusto en las divisiones donde sus empresas se habían instalado fuera del territorio estadounidense. La mayoría de artículos, cuyo tema de investigación
\end{abstract}

* Costarricense. Magister Scientiae en Historia por la Universidad de Costa Rica (UCR). Profesor e investigador del Recinto de Golfito, UCR. Correo electrónico: elconejoluis@gmail.com 
ha sido la relación entre ciudades y memoria, se han restringido a estudiarlas desde concepciones derivadas del nacionalismo. Este artículo demuestra cómo las empresas también generan y construyen memorias por medio de sus diferentes dependencias. De igual manera se constata cómo toda la política de bienestar corporativo que proyectó la United Fruit Company, buscaba mayoritariamente legitimar y respaldar su presencia en la región centroamericana.

Palabras claves: ciudades bananeras; economía de enclave; empresa transnacional; memoria colectiva; United Fruit Company; Centroamérica; historia.

\begin{abstract}
This article aims to analyze, from the history of the organizations, the relationship between memory and the banana cities built by the United Fruit Company in Central America during the 20th century. It is based on the ideas put forward by Charles Booth, Peter Clark, Agnes Delahaye, Stephen Procter and Michael Rowlinson regarding the use of the history of organizations and how from this perspective companies build a historical legacy for their employees and the general public. Using company printed sources, as well as written testimonies of former banana workers, the research tries to identify how banana cities were converted and built as places of memory. The banana city arises from the programs of the so-called "corporate welfare" of the beginning of the previous century, which sought, among other things, not only the loyalty of employees, but also that they feel well and at ease in the divisions where their Companies had settled outside US territory. The majority of articles, whose research has been the relationship between cities and memory, have been restricted to study them from conceptions derived from nationalism. This article demonstrates how companies also generate and construct memories through their different dependencies. In the same way, it can be seen how the whole corporate welfare policy of the United Fruit Company was mainly aimed at legitimizing and supporting its presence in the Central American region.
\end{abstract}

Keywords: Banana Cities; Enclave Economy; Transnational Corporations; Collective memory; United Fruit Company; Central America; History.

\title{
Introducción
}

Las ciudades son creadas con una intencionalidad y propósito que responden a los intereses y al contexto al cual pertenecen. Monumentos, estatuas, parques y otras edificaciones no solo determinan el recuerdo de algún evento empresarial, religioso, nacional, local o global, sino que también se convierten en reflejo de divisiones sociales, ordenamientos urbanos, así como lecturas paisajísticas. ${ }^{1}$

1 Greg Grandin, Fordlandia: The Rise and Fall of Henry Ford's Forgotten Jungle City (New York, EE. UU.: Metropolitan Books, 2009). Anthony D. King, Colonial Urban Development: Culture, Social Power and Environment (Inglaterra: Routledge, 1976). John M. Mackenzie, Propaganda and Empire. The Manipulation of British Public Opinion (1880-1960) (Manchester, Inglaterra: Manchester University Press, 1984). 
Dentro de estos espacios, élites nacionalistas e inclusive religiosas de diversas partes del globo han construido discursos y simbolismos que convierten a las ciudades o a partes de ellas en elementos dignos de recordar, venerar y mantener intactas para las generaciones futuras.

Autores como Maurice Halbwachs con su concepto de memoria colectiva ${ }^{2}$ o Pierre Nora con Les Lieux de Memoire ${ }^{3}$ han construido un marco analítico importante a la hora de abordar los estudios de la memoria en las ciudades o en algunas edificaciones de estas. Si bien es cierto, estos estudios parten del desarrollo de procesos nacionalistas forjados por las elites económicas, políticas, académicas y religiosas de los países, los autores invitan a la exploración de otras fuentes que expliquen el origen y desarrollo de estos procesos cargados de simbolismo, legitimación y manipulación.

Desde la historia empresarial, el concepto de memoria social parece ser el más acertado para estudiar este tipo de análisis, pues busca estudiar la manera en cómo las empresas generan memoria a través de diversos medios de comunicación empresarial, conmemoraciones, etc.

Desde la teoría de las organizaciones se ha reconstruido la memoria social y colectiva de organizaciones, así como el simbolismo del pasado con ayuda de teorías y propuestas metodológicas como los "lugares de la memoria" de Pierre Nora.

Partiendo de este hecho, la historia de las organizaciones amplía el campo de acción de estudios de una empresa y sus repercusiones pues:

\footnotetext{
“-...incluye el significado que una organización tenía para sus miembros en el pasado.

-... incluye el significado que el pasado de una organización tiene para sus miembros en el presente, lo que trae a colación la relación que hay entre lo que esas personas recuerdan del pasado y la historia documental.

-e incluye los métodos mnemónicos, como los eventos conmemorativos o la creación de lugares de memoria, a través de los que las organizaciones, entendidas como comunidades de memoria, recuerdan su pasado". ${ }^{4}$
}

Todos estos aspectos nos evidencian el proceso llevado a cabo por las empresas para construir "memoria", pues no solamente hacen una construcción del pasado, sino que también utilizan métodos, crean espacios y documentos como revistas empresariales, afiches, películas y otros recursos como ciertos

2 Maurice Halbwachs, La memoria colectiva (Zaragoza, España: Prensas Universitarias de Zaragoza, 2004), $131-162$.

3 Pierre Nora, "Between Memory and History: Les Lieux de Mémoire", Representations (EE. UU.) número especial, 26 (primavera, 1989): 7-24, DOI: http://dx.doi.org/10.2307/2928520.

4 Charles Booth, Agnes Delahaye, Michael Rowlinson, Stephen Procter y Peter Clark, "La memoria social en las organizaciones. Los métodos que las organizaciones usan para recordar el pasado", Revista Empresa y Humanismo (España) 9, n. 2 (2005): 122-123, URL: http://hdl.handle.net/10171/7003. 
edificios en ciudades compañía para legitimar esas construcciones y la solidez de una empresa.

La definición de ciudad, pero ahora desde el punto de vista europeo durante los procesos de expansión-colonización a nivel global durante los siglos XVIII, XIX y XX, se convirtió en un referente de lo novedoso, lo poderoso y lo opuesto a la naturaleza y lo salvaje. Desde esta perspectiva, la construcción de "ciudades bananeras" por parte de la United Fruit Company (UFCo) ${ }^{5}$ en Centroamérica se constituyó como una continuación de esos procesos de expansión-colonización durante buena parte del siglo anterior.

A inicios del siglo XX, empresas multinacionales estadounidenses como la Ford, Standard Oil y la UFCo se trasladaron a la región latinoamericana y el Caribe insular produciendo, explotando y exportando recursos naturales, con el fin de diversificar el mercado estadounidense. ${ }^{6}$

Dentro de esta dinámica, y como respuesta al proceso de evolución en las corporaciones multinacionales estadounidenses durante buena parte del siglo $\mathrm{XX}$, estas empresas crearon y legitimaron un modelo dirigido hacia sus empleados, conocido como "bienestar corporativo". Este modelo, para inicios del decenio de 1910, se convirtió en uno de sus ejes centrales para el desarrollo y consolidación de las empresas, tanto en su país de origen como en las regiones donde se posicionaron fuera de él.

Asimismo y después de las guerras mundiales, el bienestar corporativo incorporó también actividades de ocio para los empleados, así como una serie de acciones y procesos que buscaban generar en de los trabajadores de estas empresas valores como lealtad, fidelidad y aprecio hacia ellas. ${ }^{7}$

$5 \quad$ Alfred D. Chandler, "The Growth of the Transnational Industrial Firm in the United States and the United Kingdom: A Comparative Analysis", The Economic History Review (Gran Bretaña) nueva serie, 33, n. 3 (agosto, 1980): 396-410, DOI: http://dx.doi.org/10.2307/2595196; John S. Garner, "Leclaire Illinois: A model Company Town (1890-1934)", Journal of the Society of Architectural Historians (EE. UU.) 30, n. 3 (octubre, 1971): 219-227, DOI: http://dx.doi.org/10.2307/988748.

6 Jeffrey Jacob Jones, The World Was Our Garden: U.S. Plant Introduction, Empire, and Industrial Agri(culture) (1898-1948) (Tesis doctoral, Purdue University, 2004); Gilbert M. Joseph, Catherine C. LeGrand y Ricardo D. Salvatore (eds.), Close Encounters of Empire: Writing the Cultural History of U.S.-Latin American Relations (Durham y Londres, Inglaterra: Duke University Press, 1998); Camilo Quintero Toro, “En qué anda la historia de la ciencia y el imperialismo? Saberes locales, dinámicas coloniales y el papel de los Estados Unidos en la ciencia en el siglo XX", Historia Crítica (Colombia) 31 (enero-junio, 2006): 151-172, DOI: https://doi.org/10.7440/histcrit31.2006.06; Steve Striffler y Mark Moberg (eds.), Banana Wars: Power, Production and History in the Americas (Durham, Carolina del Norte, EE. UU.: Duke University Press, 2003); Richard P. Tucker, Insatiable Appetite: The United States and the Ecological Degradation of the Tropical World (Lanham, Maryland, EE. UU.: Rowman \& Littlefield, 2007); Ricardo D. Salvatore, Imágenes de un imperio: Estados Unidos y las formas de representación de América Latina (Buenos Aires, Argentina: Editorial Sudamericana, 2006).

7 Elizabeth Fones-Wolf, "Industrial Recreation, the Second World War, and the Revival of Welfare Capitalism (1934-1960)", The Business History Review (EE. UU.) 60, n. 2 (verano, 1986): 232-257, DOI: http:// dx.doi.org/10.2307/3115308. 
Uno de esos procesos se orientó también hacia la construcción de ciudades de empresa o compañía -Company Town-, cuyo principal objetivo se centraba en construir en los territorios extranjeros donde se habían ubicado las empresas multinacionales, edificaciones que permitieran a los empleados estadounidenses sentirse como en casa.

Estas tenían que dar una sensación de confortabilidad y seguridad que permitiera al trabajador estadounidense sentirse bien y a gusto a pesar de estar lejos de su país. En ese sentido, aspectos como el control de la temperatura, disposición, tamaño y comodidad de la casa, así como los edificios orientados para el recreo y entretenimiento, debían emular los estilos de viva de los EE. UU. De igual manera fueron constituidas para mejorar los procesos productivos y la eficiencia de las plantaciones o proyectos en las divisiones de las empresas.

Ciudades bananeras como las ubicadas en Limón, Quepos y Golfito en Costa Rica; Tela y Puerto Castilla en Honduras, Tiquisate en Guatemala o Almirante y Puerto Armuelles o Bocas del Toro en Panamá brindaron a los trabajadores estadounidenses contratados por la UFCo, vivir en un lugar que, a pesar de estar lejos de su país, se debía sentir lo más próximo a estar en los EE. UU. ${ }^{8}$

La idea de generar un espacio como en "casa", que se lee en la parte de abajo en la imagen 1, es un ejemplo de la forma en que desde la empresa se exponían las capacidades para crear en países lejanos acondicionamientos para sus trabajadores.

Este tipo de imágenes eran constantes en los diferentes números de la revista empresarial Unifruitco, que era dirigida principalmente a sus empleados que trabajaban en las diferentes divisiones. Para este caso particular, la imagen aparece en la revista dedicada a celebrar los cincuenta años de la multinacional en la región.

Aspecto, que como se indica desde el enfoque de la historia de las organizaciones, las empresas utilizan con fines propagandísticos legitimando su estabilidad por medio de sus buenas cualidades, que en este caso sería la de crear espacios para que sus empleados se sintieran en casa.

La lealtad generada por el bienestar corporativo y sus proyectos como las ciudades bananeras influyeron para que los trabajadores o Ufers $^{9}$ tuvieran un recuerdo muy agradable acerca de lo que significó vivir en estas ciudades ubicadas en los países huéspedes donde la multinacional se instaló.

8 Jason M. Colby, The Business of Empire: United Fruit, Race and U.S. Expansion in Central America (Nueva York, EE. UU.: Cornell University Press, 2011); Henning Jensen-Pennington, "Sintaxis del espacio y narrativa del poder: arquitectura en Golfito", Revista Reflexiones (Costa Rica) 91, n. 1 (2012): 199206, URL: https://revistas.ucr.ac.cr/index.php/reflexiones/article/view/1495.

9 La etiqueta Ufers para los trabajadores bananeros se puede encontrar con mucha frecuencia en los diferentes artículos de la revista de la empresa, Unifruitco. Ver por ejemplo, revista Unifruitco (agosto, 1949): 22. 


\section{Imagen 1 \\ Ciudades bananeras ubicadas en las plantaciones de banano en Bocas del Toro, Panamá, 1913.}

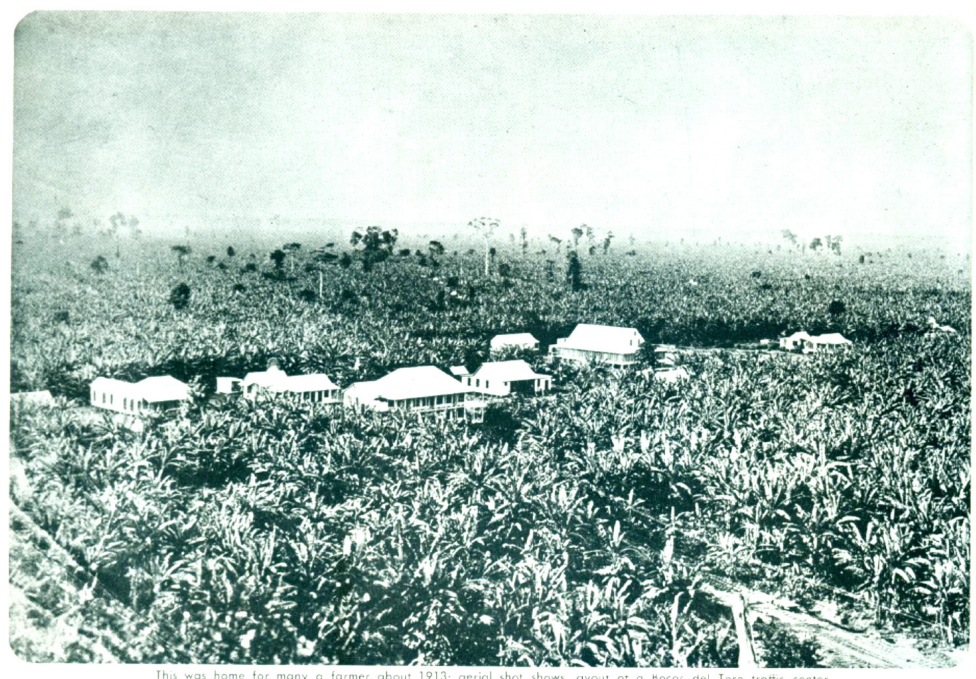

Fuente: Revista Unifruitco, "Farm life" (junio-julio, 1949): 14. La imagen expone una parte de la ciudad bananera en una finca.

El presente artículo busca analizar desde el enfoque de la historia de las organizaciones, el proceso de construcción y creación de memorias colectivas y espacios de la memoria que la United Fruit Company desarrolló para sus ciudades bananeras. A partir del estudio de material empresarial y propagandístico de la multinacional, así como un estudio de testimonios de extrabajadores bananeros, es que nos proponemos realizar el presente estudio.

Para lograr ese objetivo nos planteamos las siguientes partes del trabajo. La primera trata de explicar el origen, propósito y finalidad de las ciudades bananeras. Se parte que este tipo de ciudad es una continuación de la construcción de las ciudades jardín y ciudades empresa de finales del siglo XVIII e inicios del XX y que con el advenimiento del bienestar corporativo de la década de 1920, van a alcanzar el máximo grado de generadoras de memoria en sus empleados.

En la segunda parte estudiamos las prácticas mnemónicas de la multinacional y cómo estas generaron en las ciudades bananeras lugares de la memoria, así como una memoria colectiva en los empleados. Lo anterior con base en testimonios de extrabajadores bananeros y material propagandístico fabricado por la UFCo. Terminando con una tercera parte de conclusiones del trabajo. 


\section{Una reseña de las ciudades bananeras: origen, finalidad y propósito en el contexto empresarial de los siglos XIX y XX}

\section{El origen: de las ciudades jardín a las ciudades bananeras}

La historia de las empresas multinacionales estadounidenses y su impacto en Latinoamérica ha generado una serie de investigaciones de diferente índole. Temáticas como el género, la división social, los conflictos étnicos, así como la manipulación de estas empresas en procesos políticos en los países de la región donde se hospedaron, son solo algunos casos de estudio que han dejado como legado estas empresas..$^{10}$ Así, enfoques como el estructuralista, el desarrollista o el marxista, han marcado y subrayado la visión negativa o positiva del establecimiento de estas empresas en Latinoamérica.

La United Fruit Company es una de esas empresas que dejó huella en los países donde se ubicó. Mayoritariamente se dedicaba a la producción, exportación del banano y en menor medida del cacao, abacá, palma africana, cítricos y viajes de recreación para el público estadounidense. Esta transnacional nace en 1899 de la asociación entre A. W. Preston, Minor Keith y el capitán L. D. Baker. ${ }^{11}$

El caso de la UFCo es interesante pues desde su fundación y penetración en la región centroamericana, una de sus características fue construir ciudades tanto en las fincas bananeras como fuera de ellas. Estas ciudades contaban con casas, centros de recreación, hospitales, iglesias, puertos, escuelas, bancos, estaciones de radio y locales comerciales para sus empleados.

La lógica de estas ciudades no era nueva, de hecho los británicos fueron pioneros en construir este tipo de espacios "controlados" en los territorios donde se encontraban sus intereses económicos y políticos. ${ }^{12}$

Estos espacios se debían convertir en catalizadores de las molestias que los empleados pudieran sufrir por el hecho de estar fuera de su país, también se desarrollaron como espacios donde los empleados y después sus familias se sintieran cómodos, protegidos y respaldados por su empresa.

Con esta tarea por delante, las compañías diseñaban aéreas y actividades que les permitiera a los empleados distraerse, sentirse a gusto y empezar a

10 Mauricio Menjívar Ochoa, "De productores de banano y de productores de historia(s): La empresa bananera en la región atlántica costarricense durante el período 1870-1950, en la mirada de la historiografía en Costa Rica (1940-2002)", Istmo. Revista Virtual de Estudios Literarios y Culturales Centroamericanos, 13 (julio-diciembre, 2006), URL: http://istmo.denison.edu/n13/articulos/productores.html; Lara Putnam, Company They Kept: Migrants and the Politics of Gender in Caribbean Costa Rica (18701960) (Chapel Hill, EE. UU.: University of North Carolina Press; Ileana Rodríguez, Hombres de empresa, saber y poder en Centroamérica: identidades regionales, modernidades periféricas (Managua, Nicaragua: IHNCA-UCA, 2011); Striffler y Moberg (eds.), Banana Wars...

11 Revista Unifruitco, "The Formation of United Fruit" (junio-julio, 1949): iv.

12 Anthony D. King, Colonial Urban Development: Culture, Social Power and Environment (Londres, Inglaterra: Routledge, 2007). 
generar buenos recuerdos de esos espacios. Las empresas eran conscientes de que el lugar de trabajo se diferenciaba claramente de las casas donde se vivía, y que este aspecto solo se podía subsanar si los empleados lograban alcanzar una sensación de bienestar en esos lugares.

En los trabajos de Ebenezer Howard, por ejemplo, empezamos a escuchar acerca de las Garden Cities -ciudades jardín-. Estas ciudades jardín surgieron, según Howard, debido a los procesos acelerados de industrialización y por consiguiente de deshumanización. Las personas que vivían en las ciudades cerca de las fábricas se habían alejado de las leyes biológicas e instintos sociológicos. Estas ciudades se justificaban por razones religiosas, éticas y de salud.

El objetivo principal era lograr integrar las comodidades de la vida rural con el desarrollo industrial y sanitario. Las casas, además de un jardín donde sus habitantes pudieran distraerse de la ajetreada vida industrial, les debían servir como revitalizador de la salud mental y física. ${ }^{13}$

Paralelamente al proceso industrial y a inicios del decenio de 1890, surgen las Company Town -ciudades compañía-, que al igual que las ciudades jardín, aparecen como consecuencia de las valoraciones que se realizaron durante el desarrollo de la Revolución Industrial y expansión imperialista europea y estadounidense. Estas ciudades debían simbolizar, a diferencia de las ciudades jardín, todos los aspectos del ambiente industrial. De hecho, las ciudades para los empleados se encontraban en la misma propiedad o muy cercanas de donde se ubicaba la fábrica o las plantaciones.

Originalmente los dos tipos de ciudades se ubicaron en países como Inglaterra y EE. UU. Luego, esa idea se trasladará a los lugares donde predominaban los intereses económicos y geopolíticos de estos países. Estas ciudades compañía partían de postulados como: a) que una autoridad central debía planificar la construcción de estos espacios; b) se debía realizar un tipo de casa "estándar" para cada tipo de empleado y su condición familiar; c) los espacios se clasificaban según permanencia, tamaño del grupo familiar, así como posición laboral dentro de la empresa. ${ }^{14}$

Estas reglas, en la mayoría de los casos, son las evidencias más claras de cómo el bienestar corporativo caló muy profundo en el proceso de expansión de las empresas transnacionales, así, la estandarización de la arquitectura de las casas, como la construcción de espacios para compartir o disfrutar del ocio de los empleados son características comunes en todas las ciudades bananeras construidas por la UFCo en Centroamérica.

Estos espacios de ocio son tal vez los que más nos interesan, pues no solo se buscaba que las personas llegaran ahí, se buscaba que se sintieran juntas, felices

13 Dugald Macfadyen, "Sociological Effects of Garden Cities", Social Forces (Reino Unido) 14, n. 2 (diciembre, 1935): 250-256, DOI: http://dx.doi.org/10.2307/2571257.

14 James Walter Martin, Cultures of Business, Work and Leisure in the United Fruit Company's Caribbean (1880-1940) (Tesis Doctoral, University of New Mexico, 2008). 
y en un lugar donde normalmente podían repetir actividades que la empresa fabricaba para ellas con el objetivo de aumentar la fidelidad para ella. Asimismo, la idea de una autoridad central nos puede indicar la forma en cómo las empresas y sus ejecutivos iniciaban el proceso de construir el simbolismo para estas ciudades.

Tanto las ciudades jardín como las ciudades empresa, desde su misma categorización, construyen y generan un deseo de ser recordadas de manera distinta a las "otras" ciudades. Tomando como base a Halbwachs, lo material nos genera recuerdos y los lugares reciben huellas de los grupos y existen ciertas relaciones jurídicas y económicas que por ejemplo, para este caso concreto, determinan un deseo expreso de diferenciar estos espacios del resto de las ciudades donde vive la gente de los países donde las divisiones bananeras se instalaban. ${ }^{15}$ Las ciudades compañía son lugares donde los trabajadores pueden sentirse bien no solo por las comodidades que la empresa busca para ellos, sino que también es un espacio diferenciador con respecto a las otras ciudades de los países huéspedes donde se ubicaron.

\section{Propósito y finalidad: el bienestar corporativo en las ciudades bananeras de la UFCo}

Como hija del siglo XX, la empresa multinacional aplicó la dinámica y procesos que regían para las compañías de la época, en ese sentido ideas como el taylorismo, la producción en masa, la visión utilitaria de la naturaleza, entre otras, eran los referentes que se utilizaban para medir la eficacia o no de una compañía. ${ }^{16}$

Aunque la compañía se esforzara por lograr esos propósitos con las ciudades compañía, el contexto laboral de la época despertó el surgimiento de organizaciones laborales que buscaban más garantías y mejoras para los empleados en diferentes espacios de la empresa.

Detrás de ese contexto es que surge el concepto de bienestar corporativo que tendrá su época de mayor auge en el decenio de 1920. El bienestar corporativo trataba de evitar el unionismo laboral a partir de la premisa de que si el empleado se sentía a gusto en la empresa para la cual trabajaba, no habría necesidad de organizarse para luchar por mejores condiciones laborales. Con ese objetivo, las empresas empezaron a desarrollar una serie de programas que buscaban generar en el empleado sentimientos positivos hacia la empresa.

La creación de bonos navideños, fiestas para los empleados, reconocimientos por años laborados, organizar actividades deportivas e inclusive construir casas, así como celebrar con los empleados los años y la duración de la

15 Halbwachs, La memoria colectiva.

16 Jesús María Valdaliso y Santiago López, Historia económica de la empresa (Barcelona, España: Editorial Crítica, 2011). 
empresa, fueron elementos que buscaban que el empleado fuera construyendo una afinidad y lealtad hacia la empresa para la cual laboraba. ${ }^{17}$

Partiendo del fomento del bienestar corporativo de inicios del siglo XX y la clasificación de ciudades jardín y compañía, podemos aseverar que en gran medida las ciudades que se construyeron en las divisiones bananeras de la UFCo lograron integrar estos conceptos en sus ciudades y los mejoraron.

Este tipo de edificaciones -que valga recordar no solo la UFCo construyó, sino que también la Ford en Brasil ${ }^{18}$ y Hershey en $\mathrm{Cuba}^{19}$ por citar otros dos ejemplos muy significativos- fueron tomando vida propia como elementos que, dentro de la estructura de estas empresas, se convertían en testimonios materiales de la avanzada de la modernidad y la civilización que estaba llegando a la región; gracias al establecimiento de este tipo de compañías o al menos eso es lo que los diferentes elementos propagandísticos de la compañía nos exponían.

Las ciudades bananeras, desde la perspectiva de la UFCo, no solo fomentaban buenas relaciones entre los jefes y los empleados del mismo origen nacional de la empresa, sino que se convirtieron también en ejemplos a seguir para las otras transnacionales estadounidenses que se instalaron en la región..$^{20}$

En ese sentido, no debemos olvidar que este tipo de edificaciones también tenían una estructura excluyente. Trabajos como los de Bourgois, ${ }^{21}$ Colby ${ }^{22}$ y Jensen, ${ }^{23}$ destacan cómo las ciudades bananeras de la UFCo tuvieron como criterio del ordenamiento urbano el "separar" con criterios raciales a sus empleados. La división se contemplaba de la siguiente manera: a) una zona blanca -asignada para los empleados de mayor rango y de origen estadounidense o europeo-; b) una zona amarilla -asignada a empleados no blancos de mediana jerarquía- y; c) una zona gris -para los empleados de menor rango no blancos-.

Sí es importante mencionar que este criterio de "separación" era cuidadosamente permeado por campañas de la empresa donde se afirmaba la unión y fraternidad entre las diferentes etnias que trabajan con la transnacional. Sin

17 Fones-Wolf, "Industrial Recreation, the Second World War...".

18 Grandin, Fordlandia...

19 Thomas R. Winpenny, "Milton S. Hershey Ventures into Cuban Sugar", Pennsylvania History: A Journal of Mid-Atlantic Studies (EE. UU.) 62, n. 4 (otoño, 1995): 491-502, ULR: https://www.jstor.org/ stable/27773847.

20 May y Galo Plaza Lasso, La United Fruit Company en América Latina. Séptimo caso de estudio de la serie de la NPA acerca de la empresa estadounidense en el extranjero (EE. UU.: National Planning Association, 1958).

21 Philippe Bourgois, "Conjugated Oppression: Class and Ethnicity among Guaymi and Kuna Banana Workers”, American Ethnologist (EE. UU.) 15, n. 2 (mayo, 1988): 328-348, URL: https://www.jstor.org/stable/644760; Philippe Bourgois, Banano, etnia y lucha social en Centroamérica (San José, Costa Rica: Departamento Ecuménico de Investigaciones, 1994).

22 Vale la pena aclarar que recientes estudios muestran cómo esas divisiones que en teoría se modelaron para separar a los empleados -ya fuera a causa de la empresa o debido a la dinámica de la ciudad bananera- no siempre perpetuaron esas diferencias. La mezcla de culturas se dio y fue parte de la vida cotidiana de las ciudades bananeras. Colby, The Business of Empire...

23 Jensen-Pennington, "Sintaxis del espacio y narrativa del poder...". 
embargo, después de ciertas horas, los no estadounidenses no podían pasar al lado blanco.

Este doble discurso permite evidenciar una de las técnicas que la empresa utilizaba para generar recuerdos y construir memoria. La ciudad y sus edificios eran diferentes dependiendo de la zona donde se construyeran, las casas más grandes y con jardines pertenecían a los altos ejecutivos. En esta sección de la ciudad bananera se encontraban el edificio administrativo, piscinas, cancha de golf y lo que se conocía como el Club Centro, lugar diseñado para proyección de películas, celebración de fiestas particulares o de la empresa y que en varias ocasiones, sobre todo en las actividades oficiales de la UFCo, todos los empleados podían asistir.

Como se ve, existe una separación espacial evidente y esa misma diferenciación es utilizada por la empresa para mostrar a los empleados que en ocasiones la diferencia desaparece. Esas ocasiones, por supuesto, las indica la compañía transnacional.

Dentro de esta línea, los estudios de Putnam y Bourgois, han evidenciado, por ejemplo, la predilección de los empleadores de la UFCo para con los trabajadores de origen afrocaribeño por el dominio del idioma inglés o la manera en como fomentaban las rivalidades étnicas para frenar el aumento de trabajadores para los movimientos sindicales.

La multinacional era consciente de la importancia y del peso de la etnia, por lo tanto y en ánimo de trabajar de la manera más cómoda, siempre se esforzó para que las diferencias raciales fueran vistas más como una construcción de los locales que una fabricación por parte de la compañía.

Algo interesante en las divisiones bananeras, es que por norma existía una ciudad bananera donde se centraban los procesos técnico-administrativos y otras ciudades bananeras que se desarrollaban alrededor de las fincas bananeras como el caso de la imagen 1 del presente trabajo. En ambos casos existían los edificios para reunir a los empleados por motivo de celebraciones empresariales, reuniones $u$ otras actividades.

Debemos aclarar que la conceptualización de la ciudad jardín se aplicó mayoritariamente en las zonas donde vivieron los empleados de mayor rango de la transnacional frutera, mientras que el concepto general de la ciudad compañía fue aplicado en las otras zonas de la ciudad bananera, así como en las "ciudades" que se construyeron en las fincas bananeras.

Queda claro que la ciudad bananera fue una creación con un propósito de acomodamiento y generadora de memoria. Que si bien es cierto propiciaba una separación del espacio, esta separación se podía difuminar con cierta facilidad.

Lo anterior, en el sentido de que espacios como el Club Centro, las canchas de fútbol o terrenos donde se pudieran practicar los deportes de los jefes como el beisbol, el críquet $\mathrm{u}$ otros daban la sensación a los empleados de menor 
categoría salarial la oportunidad de compartir con los jefes y existía la impresión de que en esos espacios todos eran iguales gracias a la pertenencia de la empresa.

Las ciudades bananeras se convirtieron en espacios de intercambio cultural. También y en gran medida por la capacidad de representación que tuvo la UFCo se convirtieron es espacios que desarrollaron un simbolismo importante para las personas que las habitaron, aspecto que trabajaremos en el siguiente apartado.

En ese sentido, la ciudad bananera de la compañía multinacional se puede definir como las edificaciones construidas por la UFCo en sus divisiones bananeras. Las divisiones se organizaban en fincas y zonas administrativas donde normalmente se ubicaban los muelles y las jefaturas de la división. Tanto en las fincas como en las zonas administrativas se construían casas separadas por jerarquía ocupacional y centros de reunión empresarial como el Club Centro.

\section{Ciudades bananeras y lugares de la memoria desde la historia de las organizaciones: una propuesta de análisis}

Como se mencionó en el resumen e introducción de este trabajo, los estudios que hablan acerca de la relación entre ciudades y memoria mayoritariamente se han acogido a investigaciones que están ligadas a procesos nacionalistas, religiosos o de conflictos y traumas generados por estos. ${ }^{24}$

De hecho, Maurice Halbwachs nos explica cómo no hay memoria colectiva que no se desarrolla dentro de un marco espacial. Este autor también indica que, en ciertas ocasiones, relaciones jurídicas, grupos económicos y sociedades religiosas se superponen a las sociedades locales; dicho en otras palabras, trascienden más allá de un lugar en particular generando procesos de construcción de memorias.

De manera similar, Pierre Nora nos anunciaba la importancia de construcciones como monumentos, edificios $u$ otras edificaciones materiales, pues en estas construcciones podíamos encontrar una realidad histórica y una realidad simbólica, que para el autor es la más importante.

Para ambos autores, estos espacios ocupan un lugar importante no solo como lugares donde la memoria actúa, sino donde la memoria de las personas encuentra un punto de referencia. De igual manera para estos autores, esta es una

24 David Díaz Arias, Crisis social y memorias en lucha: Guerra civil en Costa Rica (1940-1948) (San José, Costa Rica: EUCR, 2015); David Díaz Arias, "Memoria colectiva y ceremonias conmemorativas. Una aproximación teórica", Diálogos. Revista Electrónica de Historia (Costa Rica) 7, n. 2 (2007): 170-191, DOI: https://doi.org/10.15517/dre.v7i2.6198. Alejandro Bonilla Castro, El retrato del recuerdo y el olvido: políticas de conciliación, olvido y memorias emblemáticas de la dictadura de Federico Tinoco Granados (1917-1963) (Tesis de Maestría Académica en Historia, Universidad de Costa Rica, 2013); Alejandro Bonilla Castro, "El retrato del recuerdo y el olvido. Políticas de conciliación, olvido y memorias emblemáticas de la dictadura de Federico Tinoco Granados (1917-1963)", Diálogos. Revista Electrónica de Historia (Costa Rica) 16, n. 1 (2015): 63-83, DOI: https://doi.org/10.15517/dre.v16i1.15379. Ignacio Dobles Oropeza, Memorias del dolor: Consideraciones acerca de las Comisiones de la Verdad en América Latina (San José, Costa Rica: Editorial Arlekín, 2009). 
construcción social que se ve y elabora por los grupos sociales a los cuales la persona y la sociedad pertenecen..$^{25}$

Las empresas se pueden ver como organizaciones que tienen un fin, necesitan de empleados y otros puestos necesarios para la cabalidad de las distintas operaciones que ellas desarrollan. A inicios del siglo XX, las empresas estadounidenses comienzan una nueva etapa de expansionismo en la región latinoamericana, respaldada no solamente por su país de origen, sino que también por la invitación de ciertos sectores políticos de los países latinoamericanos.

Para el caso concreto de Centroamérica, la UFCo desde su fundación ya poseía diversos territorios que habían sido otorgados anteriormente por relaciones contractuales antiguas o como estímulo a la nueva empresa para que permaneciera en el país. ${ }^{26} \mathrm{La}$ idea de ciertos sectores políticos liberales centroamericanos fue que este tipo de empresas traían modernidad y la tan ansiada civilización. ${ }^{27}$

En ese sentido, la empresa también crecía con las demandas de un mercado que ella había construido y que necesitaba perpetuar.

Este tipo de organizaciones, en especial desde el decenio de 1920, se dio cuenta de la importancia de departamentos como el de publicidad y relaciones públicas para legitimar su permanencia y visión positiva dentro de la competencia, así como conseguir el respaldo del público en general.

Estos departamentos también tuvieron la tarea de idealizar y dar simbolismo a ciertas estructuras construidas en las ciudades bananeras de la UFCo, que en concomitancia con los ideales del bienestar corporativo, reforzaron la representación de estos espacios como lugares donde se podía generar una memoria colectiva de carácter más empresarial.

\section{Prácticas mnemónicas por los medios de comunicación de la UFCo}

La creación de revistas corporativas como Unifruitco en 1925 demuestra una visión clara de la UFCo con respecto a cómo esa corporación podía generar fidelidad, pero también construir simbolismo e incluso conmemorar su presencia en la región centroamericana.

25 Eugenia Allier Montaño, "Los Lieux de mémoire. Una propuesta historiográfica para el análisis de la memoria", Historia y Grafia (México) 31 (2008): 165-192, disponible en URL: http://www.redalyc.org/ articulo.oa?id=58922941007; Díaz Arias, Crisis social y memorias en lucha $\ldots$.

26 Northern Railway Company, Concessions, contracts and decrees: Costa Rica (1892-1913). Railway Company and United Fruit Company (Boston, Massachussetts, EE. UU.: Press of Geo H. Ellis Co., 1914); Aragón De León, Los contratos de la United Fruit Company y las compañias muelleras en Guatemala (Guatemala, Guatemala: Editorial del Ministerio de Educación Pública, 1950); Compañía Bananera de Costa Rica, Chiriqui Land Company, United Fruit Company, Leyes, contratos y resoluciones relativos a las industrias de banano, abacá, cacao y palma africana oleaginosa (1930-1953) (Costa Rica, 1954).

27 Ronny Viales Hurtado, "Más allá del enclave en Centroamérica: aportes para una revisión conceptual a partir del caso de la región Caribe costarricense (1870-1950)", Iberoamericana (España) 6, n. 23 (2006): 97-112, DOI: http://dx.doi.org/10.18441/ibam.6.2006.23.97-111. 
El encargado de esta tarea fue el departamento de relaciones públicas, que a grandes rasgos su principal meta era crear una imagen amigable de la empresa en el público general. Este departamento, por medio de películas, revistas y otro tipo de publicaciones, edificó un modelo de lo que la ciudad bananera debía ser. Le dio un simbolismo necesario para que no solo durante la vida de la empresa, sino que también después de esta, esos espacios fueran sitios de aprecio y recuerdo para las personas que trabajaron ahí.

Esta función, que se podría interpretar cómo construir una historia bonita de la UFCo, es uno de los elementos claves que las grandes empresas estadounidenses aprendieron a dominar desde el decenio de 1920. La historia se ve como una generadora de vínculos entre la empresa, sus empleados y el público en general, pues por medio del estudio de la "historia empresarial" las personas pueden medir la fiabilidad y la durabilidad de una compañía. ${ }^{28}$ También pueden ver el progreso que la empresa ha traído a esas regiones donde se instaló fuera de los EE. UU.

Las ciudades bananeras, tanto la administrativa como las ubicadas en las fincas, ya poseían una importancia para los gobiernos locales que promovían este tipo de inversiones, inclusive se convirtieron en modelos a seguir dentro de las mismas sociedades centroamericanas. Todo esto se logró, pues como en palabras de Walter, tomadas de Greenblatt, ${ }^{29}$ esta empresa se convirtió en una máquina de representaciones. ${ }^{30}$

La UFCo organizó, planeó y distribuyó una cantidad enorme de panfletos, boletines informativos y películas cuyo principal objetivo era manifestar que su inversión en las regiones centroamericanas no solo había traído el desarrollo, sino que también había cambiado la historia de la región. Imágenes como la que encontramos en la siguiente página -imagen 2-, que fueron parte de la campaña de finales de la década de 1950, titulada como el círculo viviente, reflejan perfectamente la idea que venimos comentando.

En primer lugar, se puede ver la división que posee el círculo. A la izquierda encontramos una selva y un hombre con gran esfuerzo, cortando con su hacha los enormes árboles. A la derecha podemos observar una ciudad bananera, ${ }^{31}$ la cual ya terminada evidencia la transformación y la separación entre lo civilizado y lo salvaje.

28 Booth, Delahaye, Rowlinson, Procter y Clark, "La memoria social en las organizaciones...".

29 Stephen Greenblatt, Marvelous Possessions: The Wonder of the New World (Chicago, EE. UU.: The University of Chicago Press, 1991).

30 Otro ejemplo de la UFCo como máquina de representaciones lo encontramos en la obra de Enrique Camacho Navarro, Cómo se pensó Costa Rica: imágenes e imaginarios en tarjetas postales (1900-1930) (México, D.F.: Centro de Investigaciones sobre América Latina y el Caribe, UNAM, 2015). Aquí, el autor utiliza tarjetas postales elaboradas por la UFCo y demuestra la importancia de este tipo de documento para construir la imagen de Limón como un puerto bananero.

31 Fifty-First Annual Report to the Stockholders of the United Fruit Company, 1950. 
Divisiones bananeras y memoria: un acercamiento al legado de las ciudades bananeras de la United Fruit Company en Centroamérica durante el siglo XX

\section{Imagen 2 \\ "Yesterday the Jungle ... Today Producing Acres".}

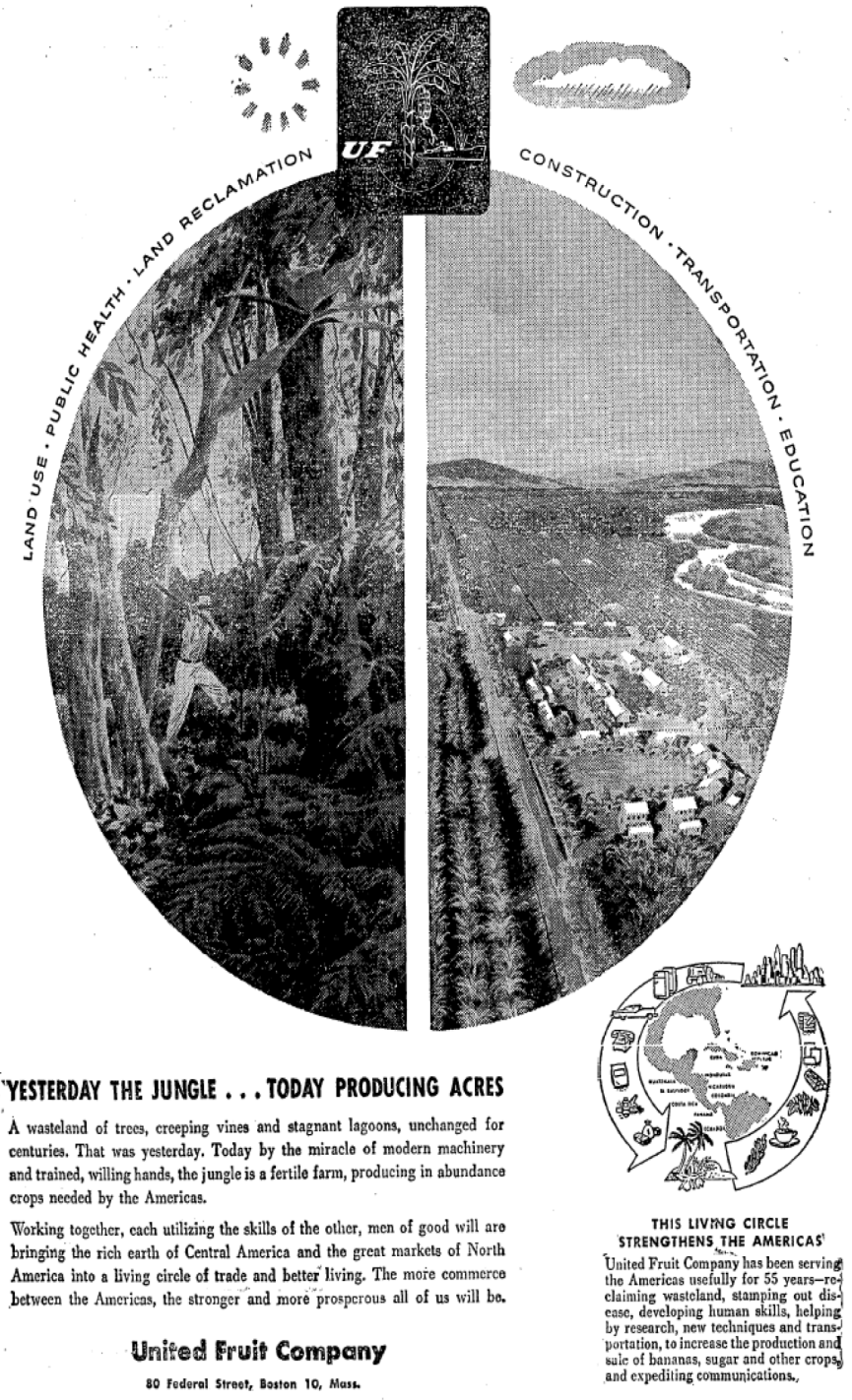

Fuente: Base de datos ProQuest Central: Barron's National Business and Financail Weekly (13 de agosto de 1956): 64.

Este simbolismo que marca un antes y un después, "un ayer y un hoy" en palabras de la empresa, evidencia no solo la importancia que le dan a este tipo de documentos para enviar sus mensajes, sino que también nos muestra una de 
las formas y métodos que la transnacional utilizaba para construir recuerdos y una memoria de lo que debían significar sus ciudades bananeras. El ayer es la selva, lo improductivo, lo salvaje, el hoy con la ciudad bananera, es fuente confiable de que el desarrollo y la civilización pueden llegar a los lugares más alejados de los EE. UU.

La imagen es reflejo también de la importancia que le dan las empresas a crear conmemoraciones a partir de logros de la compañía. El solo hecho de publicar la imagen y brindar mensajes escritos ya nos señala el cómo debe ser interpretada la conmemoración y lo que debe significar.

El texto nos detalla la batalla heroica de la empresa, y lo que tuvo que hacer con ayuda del ser humano para conseguir transformar la jungla en acres de tierra productiva.

Alrededor del círculo se nos muestran los otros aportes que trae la empresa con sus ciudades bananeras; los cuales son: hospitales, salud, uso de la tierra, construcciones, educación, transporte, entre otras maravillas. Todos estos fueron aspectos introducidos dentro del simbolismo de las UFCo y sus ciudades.

Este tipo de material impreso, que produce e induce a construir simbolismos para la ciudad bananera, fue trabajado desde el inicio de la empresa como tal. Sin embargo, a lo largo de los años y dependiendo de los contextos políticos y necesidades económicas de la compañía, dichos símbolos sufrieron mínimas transformaciones.

Para el caso particular de la imagen 2, esta se publicó en revistas de difusión masiva como la revista Life en español, y revistas dirigidas al público empresarial de los EE. UU., aspecto que nos manifiesta la importancia que le daba la empresa multinacional a la difusión a gran escala de este tipo de materiales.

Estos se pueden ver de igual manera al estilo de una estampa conmemorativa, que como se mencionó anteriormente, indica en forma precisa y por medio de dos imágenes, la evolución producida por la construcción de la ciudad bananera. La imagen se convierte en una fuente y en un testimonio de la historia construida por la compañía, por lo tanto, es un recuerdo y le brinda simbolismo a la ciudad, ya no solo es la ciudad bananera, ahora es la ciudad que hizo historia.

En la imagen 2, la ciudad no posee nombre, esto se realiza con el objeto de indicar que el hecho histórico y digno de mención que sucede en la imagen de esa ciudad bananera, se da en las otras regiones donde se encuentran las divisiones bananeras de la UFCo. La imagen narra perfectamente la historia de Tiquisate en Guatemala, Limón en Costa Rica, Tela en Honduras o Puerto Armuelles en Panamá, por citar solo unos casos.

Dentro de la historia de las organizaciones, el aspecto del cómo las empresas desean ser recordadas nos lleva a buscar este tipo de fuente que muestra a grandes rasgos las categorías que la empresa deseó utilizar para lograr ser recordada. Nos brinda un buen ejemplo de cómo se construye la historia digna de 
recordar de una empresa. Esta campaña del círculo viviente se desarrolló por el departamento de relaciones públicas a mediados del decenio de 1950.

Un aspecto interesante es que las imágenes que aparecen en la publicación eran fotografías tomadas por empleados de la misma UFCo, y en ciertas ocasiones una misma imagen podía aparecer en diferentes publicaciones de la empresa e inclusive en diferentes años. Lo anterior nos permite sugerir la existencia de una base de fotos en la compañía que podían ser utilizadas para diversos fines y a lo largo de su historia. Esta sugerencia se explica en el entendido de que otras empresas multinacionales estadounidenses tenían repositorios fotográficos muy importantes, como por ejemplo la General Elecric. ${ }^{32}$

Otro ejemplo lo encontramos en la edición especial de junio-julio de 1949 de la revista Unifruitco. El tiraje de esta edición conmemorativa del cincuenta aniversario de la empresa explica en gran medida cuáles eran los principales hitos que esta proyectaba para sí. El texto que se utiliza para explicar ampliamente el significado de la imagen de la portada nos lanza el mensaje de que, a pesar de los sacrificios y contratiempos, la UFCo se mantiene dando alimento al mundo y se consolida como empresa del sector.

El texto menciona:

"El asunto de la portada y del contenido no es sencillamente UF 'entonces y ahora'. Aunque la UF se ha multiplicado muchas veces en sus 50 años de existencia, todavía está en el mismo ramo; el de cultivar alimento para el mundo. El medio siglo de crecimiento de la UF no ha sido siempre ordenado y estable; pero al fin cada nueva empresa fue siempre sometida a régimen y plan. Y si usted da un vistazo a las operaciones modernas de la UF, verá cómo el plan salió cuenta... Si desea una exposición vívida de los primeros pasos de su construcción y de etapas periódicas de la UF, sírvase recorrer las páginas siguientes". ${ }^{33}$

La revista era distribuida en las divisiones bananeras, a diferencia de la imagen 2 que era un anuncio que aparecía en revistas como la Life y otras, como ya se mencionó. Manteniendo las diferencias, cuando en la escuela se enseña la historia de nuestro país y sus fiestas patrias a partir de la lectura y las imágenes que se encuentran en un libro de texto que nos explica con detalles la historia de los acontecimientos. Para el caso de la UFCo, la revista Unifruitco cumple esa misión. Invita al lector a que explore y conozca la historia de la empresa, por los títulos de los capítulos nos damos cuenta acerca de Jamaica, la vida en el trópico -que se da gracias a las ciudades bananeras-, la Gran Flota Blanca, lo que reserva el futuro, entre otros temas.

32 David Nye, Image Worlds: Corporate Identities at General Electric (1890-1930) (Cambridge, Massachusetts, EE. UU.: The M.I.T. Press, 1985).

33 Revista Unifruitco, 50 Aniversario (junio-julio, 1949). 
El texto se convierte en guía y evidencia fáctica de lo que la compañía ha hecho y espera realizar, da la sensación de prosperidad y estabilidad. La ciudad bananera después de 50 años puede seguir adelante. Cuando se observa y lee la revista de este número se puede ver como los puertos, la Flota Blanca, el ferrocarril y la lucha contra la naturaleza para alcanzar la civilización han sido parte del sacrificio de la empresa para lograr el objetivo de seguir existiendo. En ese sentido las estaciones del ferrocarril, el mismo tren o los barcos de la Flota Blanca son nutridos de simbolismo por parte de la UFCo y de recuerdos por aquellas personas que los utilizaron.

Los medios de transporte fueron muy utilizados por la compañía como elementos legitimadores de la llegada de la civilización a los trópicos, y aunque mayoritariamente se utilizaban para transportar productos como el banano o el abacá, también fungieron en la doble tarea de llevar y traer turistas y trabajadores a las ciudades bananeras. La edición en particular del cincuenta aniversario está cargada de simbolismos y mensajes con un fuerte contenido propagandístico, en el sentido de que el lector entienda el esfuerzo que la empresa ha desarrollado para mantenerse vigente en el área. Las ciudades bananeras con el tren y la Flota Blanca se posicionan en un papel fundamental de esa lucha. Es la evidencia más tangible del crecimiento que trajo la empresa y también la prueba de que sus empleados viven ahora no en el infierno de los trópicos, sino más bien en el paraíso de los trópicos. Esa es al menos la memoria colectiva que se espera lograr.

Otras de las fuentes muy utilizadas por la UFCo para construir memoria y lugares de la memoria son los reportes para socios. Estos también sufrieron un cambio importante en su diagramación y presentación para los socios. Con un tamaño más grande, mayor cantidad de imágenes y nuevas secciones como investigación, transporte, agricultura, entre otras, no solo se explican con más detalle ciertos departamentos de la empresa, sino que también se ilustraban el avance, crecimiento y ambiente laboral sano en las divisiones bananeras de la UFCo en Centroamérica.

Este tipo de documentos evidencian la capacidad de las empresas para generar todo lo necesario para construir, por ejemplo, la conmemoración de la construcción de una ciudad bananera. Visto desde esa perspectiva, es clara la forma y manera en como la empresa transnacional, por medio de todos los medios de comunicación existentes en la época de su apogeo, utilizó y construyó una red de materiales y construcciones tanto físicas como mentales que les permitiera a sus empleados conocer y entender la importancia de su estadía.

La ciudad bananera es vista también como el puesto de avanzada de la civilización. No es extraño encontrar en los reportes para socios de la empresa -y la revista Unifruitco en todas sus publicaciones- reportajes de cómo se construye una división bananera ${ }^{34}$ la importancia de la ciudad bananera y artículos dedicados a

34 Forty-Ninth Annual Report to the Stockholders of the United Fruit Company, 1948: 19. 
divisiones como Golfito $\mathrm{y}^{35}$ Limón $^{36}$ en Costa Rica, Tela ${ }^{37}$ en Honduras o Tiquisate $^{38}$ en Guatemala, por solo citar algunos ejemplos.

Por otro lado, la oficina de la Flota Blanca era un sitio donde los pasajeros podían comprar los tiquetes de viajes de la flota, aspecto que seguramente se aprovechaba para promocionar la visita a otras divisiones. Asimismo con la llegada de mercancías y los respectivos controles de aduana, personal de la empresa y ajeno, se podían observar los mecanismos que la empresa utilizaba para perpetuar su ideal histórico. La imagen 3 nos muestra esa práctica, y nos clarifica la importancia que daba la empresa a la imagen, en especial, el uso de fotografías. La fotografía es una copia de un instante temporal, es el reflejo de la realidad, pero también marca una imagen que tiene un significado especial en la historia.

De esta manera, la transnacional frutera visualiza y estandariza el uso de las imágenes. Como se ha analizado en este trabajo, el departamento de relaciones públicas tenía la política de repetir las fotografías en los distintos medios de comunicación de la empresa, lo cual denota el cuidado y selección de las fotografías, su misión era dejar claro el mensaje y por medio de la repetición lo que nos dejaban entender era el éxito alcanzado por la empresa.

\section{Imagen 3 \\ Fotografía de la oficinas de la Gran Flota Blanca en la división de Golfito, década de 1950.}

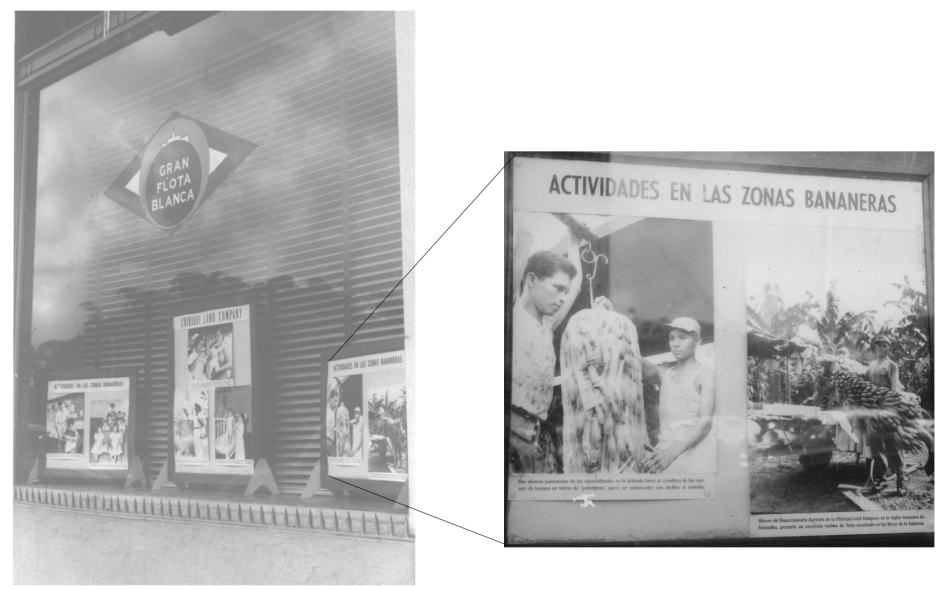

Fuente: Colección Claudio Barrantes (CBCR 11-12).

35 Revista Unifruitco (agosto, 1949): 22.

36 Revista Unifruitco (enero, 1950): 10.

37 Revista Unifruitco (abril, 1950): 12.

38 Revista Unifruitco (septiembre-octubre, 1949): 14. 
Otro ejemplo de prácticas mnemónicas y que guarda gran relación con los procesos nacionalistas en los países es la creación de textos dirigidos a niños que permitan conocer la historia de estos espacios.

Durante la década de 1950, la empresa se esforzó por mejorar las relaciones con el público latinoamericano, evidencias de esos esfuerzos fueron las publicaciones en castellano que empezaron a ser distribuidas por la UFCo en divisiones bananeras y las escuelas de los países donde estaba ubicada. Por ejemplo para el caso costarricense, durante este periodo, se distribuyó un texto titulado Golfito: una historia de la conquista de la selva.

El texto contenía pocas páginas, cargadas de muchas imágenes y poco texto que explicaban cámo en la división Golfito se habían logrado construir las edificaciones necesarias para lograr vencer a la selva costarricense en su intento de detener el progreso. Lo interesante es que el texto se creó para ser distribuido en las escuelas de este país centroamericano, con el objetivo de que los estudiantes elaboraran un ensayo acerca del texto y el ganador o ganadores recibirían como premio un viaje a la ciudad bananera de Golfito. ${ }^{39}$

La UFCo, desarrolló e inventó para sus ciudades bananeras una serie de efemérides empresariales que fueron distribuidas por los diferentes medios de comunicación de la empresa, logrando de ese modo crear una estructura fuerte que reforzara los valores propios de la empresa.

Es importante mencionar que no solo material escrito hacía uso de prácticas mnemónicas, también las películas de la empresa, Journey to Banana Land o Why the Kremin Hates Bananas, intentaban recalcar la importancia de las ciudades bananeras y el éxito que habían alcanzado.

\section{Los "banana people" recuerdan sus tiempos de Ufers}

Páginas arriba mencionamos la importancia que dieron los gobiernos latinoamericanos a la presencia e instalación de empresas transnacionales en la región.

Por ejemplo, para el caso del Golfo Dulce en Costa Rica, Leónidas Pacheco pronosticaba una gran prosperidad para este territorio en el tanto los “americanos" llegaran a establecerse, Pacheco escribía en el Eco del Pacifico:

\footnotetext{
"Golfo Dulce. Allí está el porvenir... Fue necesario que vinieran los americanos para que la zona atlántica saliera de su sopor, de su eterna malaria, de su fiebre espantosa, de su insignificancia absoluta y surgiera la vida agrícola con vigor no sospechado... Allá entre muchos está Golfo Dulce invitando nuestra dormida fibra; allá la rica península de Osa, en donde hay campo abierto para la noble lucha del trabajo y en donde mañana, al fundirse las aguas de los Océanos, será ésa, para otros la región de la codicia.
}

39 May y Plaza Lasso, La United Fruit Company en América Latina... 
Divisiones bananeras y memoria: un acercamiento al legado de las ciudades bananeras de la United Fruit Company en Centroamérica durante el siglo XX

Si las frutas son jugosas y perfumadas en el Atlántico, es materia averiguada que en el Pacífico son mil veces mejores... Cubiertos están sus bosques de maderas valiosas... Campos de bendición para el cultivo del arroz, del maíz, cacao, hule, y qué más... lo más que se quisiera... el golfo que es el sueño de un poeta; el golfo con sus dormidas ondas, seguro abrigo para todas las escuadras del mundo, camino natural, ideal, insuperable para las corrientes de importación y exportación, para hacer de aquellas vírgenes regiones el emporio comercial, la mina Golconda, el granero de la Patria, la espléndida aurora de la Bonanza". ${ }^{40}$

Este tipo de aseveraciones nos muestran las representaciones e ilusiones que algunos ciudadanos se fabricaban con respecto a las construcciones de la UFCo en la región. A simple vista uno podría pensar que era solo un ideal. Sin embargo, cuando se encuentran testimonios de trabajadores bananeros de la época del auge de la transnacional, nos damos cuenta de que varias de las categorías generadas desde el departamento de relaciones públicas de la compañía calaron muy hondo en el pensar de sus empleados.

En ese sentido, visualizar opiniones de 1955 acerca de la misma ciudad bananera de Golfito, donde se afirmaba que “... a no dudar un jardín muy bien cuidado por la Compañía Bananera, esto en cuanto a propiedades de la misma", ${ }^{41}$ nos sugieren el peso significativo que jugaron las representaciones construidas desde la empresa.

No es posible poner todos los textos de los extrabajadores bananeros, pero cuando se leen siempre queda la idea de que ellos estuvieron desde su recuerdo en un lugar privilegiado en donde se llevó la civilización a la selva. En ciertos textos de memorias escritas, como los recopilados por Clyde Stephens se autodefinen como los "banana people" 42 y guardan recuerdos de lo que significó para ellos vivir en estos espacios, en donde a diferencia de lo que la teoría de las ciudades compañía explica, todavía se tienen buenos recuerdos de la mezcla de culturas en la región. Para los trabajadores que quedaron en las ciudades bananeras después de la salida de la UFCo y la consecutiva venta de bienes a entes estatales, particulares u otras empresas transnacionales fruteras, sus extrabajadores añoran la presencia de la empresa. ${ }^{43}$

40 El texto menciona que fue extraído del Eco del Pacifico del 22 de septiembre de 1912, sin embargo, de donde se obtuvo fue de: Leónidas Pacheco, "Golfo Dulce. Allí está el porvenir", en: Nociones de geografia patria: premiadas con medalla de oro en la exposición centroamericana de Guatemala, Tomo I. Geografías físicas de la América Central, Miguel Obregón L. (comp.) (San José, Costa Rica: Imprenta Nacional, 1923), 171-173, disponible en URL: http://www.asamblea.go.cr/sd/Otras_publicaciones/Forms/ DispForm.aspx?ID=311. El resaltado del texto es mío.

41 La Nación, 28 de julio de 1955, 3. El énfasis en negrita es nuestro.

42 Clyde S. Stephens, Banana People: True Stories of the Tropics. History, Adventures \& Anecdotes of a Bygone Culture (EE. UU.: Dollar Books; Davison Tavares Florida, 2002).

43 Jonathan Warner, "People Need More Than Just Bananas: A look at Dependency Theory through the History of the Zona Sur of Costa Rica", Diálogos. Revista Electrónica de Historia (Costa Rica) 8, n. 2 (2007): 53-77, DOI: https://doi.org/10.15517/dre.v8i2.18339. 
La UFCo tuvo éxito en crear un simbolismo especial para sus ciudades bananeras, por medio de diferentes medios de difusión. Cuando se visita hoy cualquier ciudad bananera que perteneció a la transnacional se respira el recuerdo y la añoranza de los años en que estuvo trabajando. La empresa, como toda organización, diseñó y fabricó a su conveniencia una serie de recursos visuales, cinematográficos y multimodales que se distribuyeron en varios países del mundo en varios idiomas con el objetivo de generar una memoria corporativa que se opusiera a los "malintencionados" comentarios negativos generados contra la empresa. A través de recursos como la revista empresarial Unifruitco que, desde 1925, informaba a los empleados acerca de las acciones de la compañía, hasta las películas cortas que distribuía la UFCo en cines y colegios, la idea de legitimar una empresa emprendedora, eficiente y civilizadora fue el común denominador de estos recursos.

Esas ciudades también se diferenciaron de los pueblos que se desarrollaron a su alrededor sobre todo para brindar servicios. El testimonio de uno de los Ufers es bastante elocuente:

\begin{abstract}
"Golfito was a town with two faces. Part of this Costa Rica port was a United Fruit Company town where bananas were exported to far-off markets. Employees like me, with our offices and our families, enjoyed a country club lifestyle with all of amenities.... The other part of Golfito was called Pueblo Civil, or downtown Golfito, as a called it, and was the non-fruit company part of the port. Wedged between the base of a steep mountain and and the edge of Golfito Bay, this area had businesses and houses -some of ill repute-". ${ }^{44}$
\end{abstract}

Este otro Golfito no tenía espacios de ocio como el Club Centro, cancha de golf o piscinas, era el "otro" espacio, con lugares de mala reputación y no pertenecía a la UFCo. La construcción de las ciudades bananeras como lugares de la memoria es un proceso que sin duda alguna todavía se puede analizar más. Si bien es cierto en la ciudad bananera no había museos o monumentos a héroes caídos, el Club Centro, el muelle, la ciudad en sí se convertían y eran simbolizados como lugares con una importancia para los trabajadores bananeros.

Ya fuera por medio de los diferentes medios de comunicación de la empresa o por las actividades conmemorativas que realizaba, tales como reconocimientos a trabajadores con más años de trabajar ahí o celebrar el inicio de operaciones de la empresa, bailes de fin de año, juegos de futbol o beisbol, la UFCo no solo reforzaba la idea de ser un Ufer, también brindaba los elementos y recuerdos necesarios para generar un proceso de construcción de memoria colectiva.

Los trabajadores bananeros fueron bombardeados con una cantidad impresionante de información y representaciones acerca de la importancia de

44 Stephens, Banana People..., 218. 
pertenecer a la UFCo. Ya fuera en las ciudades, en las fincas o en las ciudades puerto, los trabajadores eran un grupo que si bien es cierto existían diferencias, su lugar de trabajo y el orgullo que eso podía evocar abrió el portillo para que la propaganda de la transnacional tuviera un cierto grado de éxito en su tarea de construir un buen recuerdo de trabajar para la empresa.

Esto evidentemente se fortaleció en gran parte como una respuesta a los movimientos sindicales bananeros que fueron muy fuertes. Frente a esas situaciones de movilización laboral, la empresa y su departamento de relaciones públicas idearon estrategias que lograran hacer olvidar y menoscabar la imagen negativa que se podía generar para la compañía el conocimiento de inconformidad laboral en sus divisiones. ${ }^{45}$

\section{Conclusiones}

El artículo analizó cómo la UFCo construyó y dio simbolismo a sus ciudades bananeras ubicadas en la región centroamericana durante el siglo XX. Partió de los aportes teóricos de la historia empresarial y la historia de las organizaciones, dando énfasis a la construcción de la memoria en una ciudad compañía. La ciudad bananera es hija de la ciudad jardín y de la ciudad empresa y sus características, del bienestar corporativo de la década de 1920 y su necesidad de crear ambientes confortables y adecuados para los empleados que debían movilizarse fuera de sus países de origen para trabajar en las divisiones de la compañía en el exterior. Asimismo, dio pie para que las prácticas mnemónicas se utilizaran con el objetivo de que el trabajador no solo se sintiera a gusto con la empresa, sino que también lograra el recuerdo de un lugar que le generó tranquilidad, empleo, seguridad y orgullo.

Dentro de esta línea, edificios como el Club Centro, la estación de ferrocarril, el ferrocarril, el puerto y los barcos de la Flota Blanca se convirtieron en lugares de la memoria gracias al simbolismo dado por la UFCo y sus trabajadores. Aunque la ciudad bananera estaba estratificada según el cargo que ocupaban los empleados y la entrada era restringida, espacios como el Club Centro que se ubicaba en la "zona americana o blanca" se convirtió en el lugar donde las diferencias podían desaparecer. Entre los argumentos de peso que plantea Halbwachs, este nos enseña la importancia de la idea de pertenencia a un grupo, aunque a veces existían relaciones jurídicas, económicas o religiosas que sobrepasaban los espacios y la memoria que se podía generar en ellos, las ciudades bananeras

45 United Fruit Company, Reporte para socios, 1954: 4. Edmund Witman, How an American Company, through Advertising and Public Relations, has Combatted Communism in Latin America (New York, EE. UU.: 1955). 
y los trabajadores de la UFCo tenían todos los elementos para construir y desarrollar el proceso de una construcción de la memoria en estos espacios.

Desde el punto de vista de Nora, que también aporta al enfoque de la memoria social dentro de la historia empresarial, fue claro el papel que desempeñaron la revista Unifruitco, los reportes para socios y las películas de la compañía en la divulgación de imágenes que dieron paso a la cristalización de un recuerdo en las ciudades bananeras. Las fuentes de la compañía se pueden ver como la historia oficial y su deseo de imponer su punto de vista del pasado, el uso tan importante que se le da a la fotografía, se explica en gran medida, pues la foto se concibe en la época como una copia de la realidad, es un hecho y una forma de constatar el aporte de la empresa, pero también es un documento que conservado genera una visión de la realidad que se vivió.

El uso del pasado a partir de una interpretación histórica que beneficiara a la empresa, fue un elemento medular que la compañía transnacional supo sacar el mayor provecho. Ejemplo de lo anterior fue la campaña del círculo viviente y su separación entre el ayer y el hoy. Las conmemoraciones de la empresa tuvieron toda la difusión y cuidado a la hora de ser presentadas y expuestas a diferentes públicos, a través de los medios de comunicación de la UFCo. Si bien es cierto que no todos los trabajadores guardan los mismos recuerdos acerca de vivir y trabajar en la transnacional, es claro que mucho de lo impuesto por la compañía fue aceptado y apropiado por sus trabajadores.

Queda claro que el proceso de construcción de la memoria fue bastante controlado por la empresa, en el tanto las fotografías, comentarios y el uso de estas siempre estuvieron en manos de un grupo de funcionarios que supieron cuándo repetir y qué imágenes usar dependiendo del contexto o del motivo, hecho o espacio que se deseaba recordar. A partir de los testimonios escritos de los trabajadores bananeros, se puede constatar el éxito de las prácticas para generar memoria para los empleados bananeros no solo de la clase alta administrativa, ${ }^{46}$ sino de las otras clases de menor posición socioocupacional. Sería interesante ver si esta situación se dio en las ciudades de la Fordlandia para Brasil o Hershey en Cuba. El tema queda abierto y lleno de posibilidades para investigaciones futuras.

46 Atalia Shragai, "Do Bananas Have a Culture? United Fruit Company Colonies in Central America (1900-1960)", Iberoamericana (España) 11, n. 42 (2011): 65-82, DOI: http://dx.doi.org/10.18441/ ibam.11.2011.42.65-82. 